\title{
UNDERSTANDING ADOPTION OF BIG DATA ANALYTICS IN CHINA: FROM ORGANIZATIONAL USERS PERSPECTIVE
}

\author{
K. M. Sam ${ }^{1}$, C. R. Chatwin ${ }^{2}$ \\ ${ }^{1}$ Department of Accounting and Information Management, University of Macau, Macau, China \\ ${ }^{2}$ Department of Engineering and Design, University of Sussex, Brighton, United Kingdom \\ tonysam@umac.mo
}

\begin{abstract}
Big data is a recent technology employed by companies to gain a competitive advantage. The investment of big data technologies in the USA was estimated at more than 30 billion USD in 2016. However, the investment of big data technologies in China was relatively small in 2016. Grounded in the Technology-Organization-Environment (TOE) framework, this study identifies the main factors affecting the organizational adoption of big data in China. The results can provide useful indicators for industries to utilize big data for a more productive business.
\end{abstract}

Keywords - big data analytics, TOE model, adoption intention, readiness

\section{INTRODUCTION}

Big data is one of the hottest Internet technologies that can allow businesses to manipulate all information around the physical environment for more accurate analysis of company performance in response to today's fierce competition. IDC says that worldwide revenues for big data and business analytics will grow from $\$ 130.1$ billion in 2016 to more than $\$ 203$ billion in 2020, at a compound annual growth rate (CAGR) of $11.7 \%$ [1]. In China, fiftysix big data and AI projects were qualified for state support and are in progress [2], indicating that big data technologies will be one of the main focus items in China. Despite the fact that more and more organizations are adopting big data, its diffusion is still far from realizing its full potential due to issues like: security concerns, fear of losing control, and organizational resistance [3,4]. Most of the earlier studies on big data analytics focused on technical and operational issues. A few studies have addressed the adoption of big data analytics from an organizational perspective. This study analyzes the determinants of adopting big data in organizations based on a well-known theory in innovation diffusion: Technology-Organization-Environment (TOE) framework [5]. The purpose of this study is to provide a vision for executives to fully utilize big data in organizations. Accurate assessment can provide management guidelines for the implementation of big data analytics in organizations.

\section{A. TOE Framework}

In the TOE framework, contextual factors are classified into three categories: technology, organization and environment. The technology context refers to the technologies available in organizations for possible adoption. The organization context refers to the characteristics of the company, such as: size, skills and experience. The environment context comprises market elements, competitors, and the regulatory environment. The TOE framework is different from other theories and it only suggests different sources of influence without specifying the variables in each category [6].

\section{RESEARCH MODEL}

In this study, the TOE factors relevant to big data adoption are analyzed. Most of the existing studies that adopt the TOE framework examine the effects of different types of factors on technology adoption separately [7] Such individual modeling of relationships, however, does not reflect the basic premise of the TOE framework that different sources of influences need to be examined together. To integrate the impacts of technological, organizational and environmental factors on big data adoption, there is a need for a formative construct " $\mathrm{Big}$ Data Readiness" that captures their overall effect. That is, potential users in different organizations have different considerations related to: technology, organization and environment, which largely determine how ready they are to adopt big data. The research framework linking the TOE factors with the attitudes and intention of adopting big data analytics in organizations is shown in Fig. 1.

\section{A. Big Data}

Big data has been defined in a number of different ways but is basically derived from business intelligence and analytics (BI\&A). In this research, from a business perspective, we define big data as a new technology that can create business value through its unique analytics, predictive, and decision support capabilities, which allow it to deal with data that could not otherwise be processed using traditional approaches $[8,9]$. 


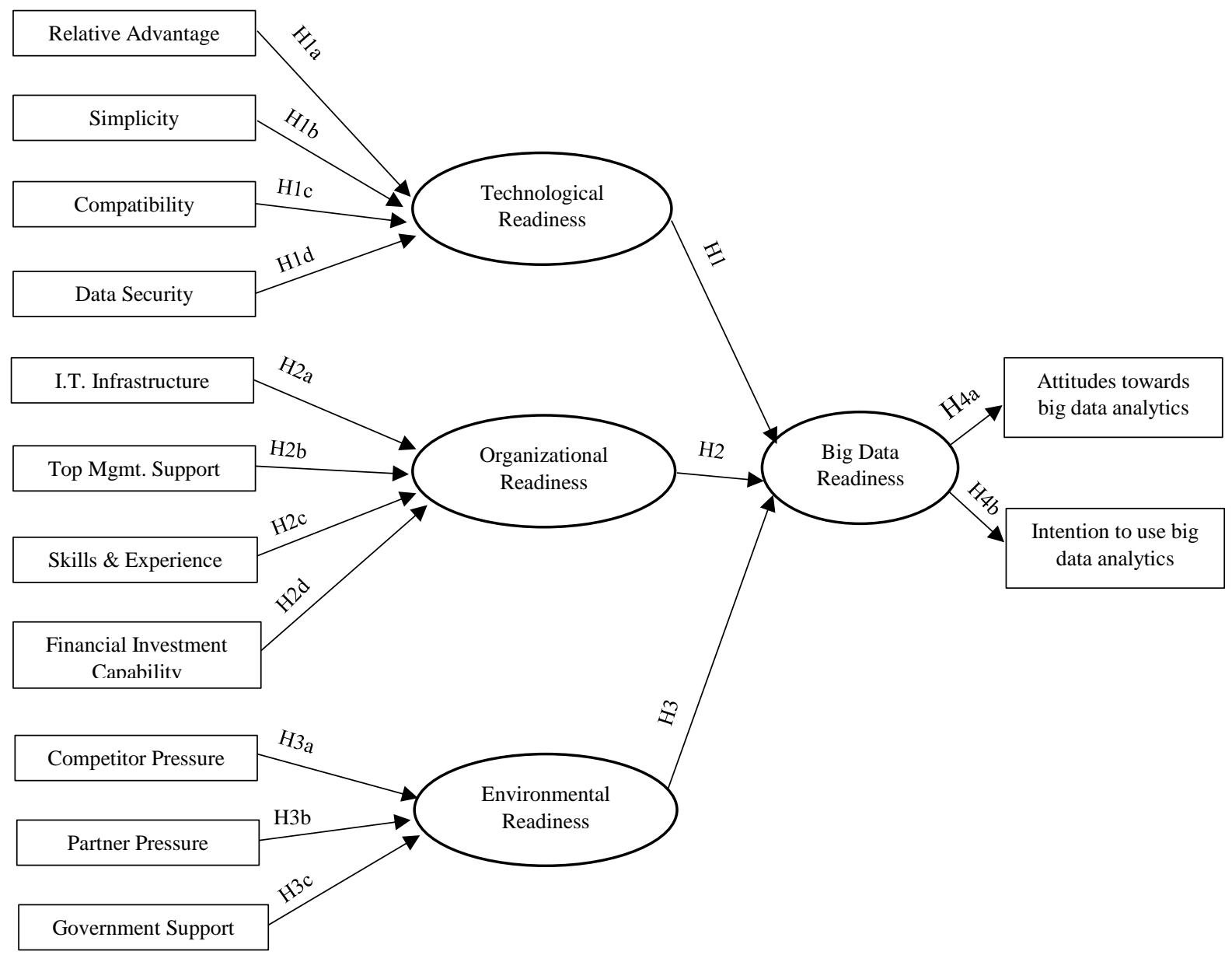

Fig. 1. Research Model

\section{B. Technological Readiness}

Technological readiness refers to how organizational users are prepared and willing to adopt big data analytics. Compared with traditional individual applications, big data analytics provides a platform for organizational users to access integrated data from multiple sources in internal and external environments. For such interoperable applications, the content domain of technological readiness should be broader [10]. According to Rogers' Innovation Diffusion Theory [11], there are several intrinsic characteristics of an innovation that influence its diffusion: (1) Relative Advantage: how improved an innovation is over the previous generation; (2) Simplicity (or complexity): whether an innovation is easy or difficult to use; (3) Compatibility: whether an innovation is compatible with current: practices, values, and needs.

First of all, organizational users need to find out how simple the solution of big data analytics is; how compatible the solution is working with current systems and judge this new technology's potential benefits [12]. Thus Relative Advantage, Compatibility and Simplicity are closely related to the adoption of big data analytics [13]. In addition, high-tech data storage and management are part of big data analytics [14]. Thus data security plays an important role in big data analytics. Besides, compatibility with existing technologies is an important factor affecting the adoption of a new technology $[12,15,16]$. As a result, their relationships with technological readiness are hypothesized as follows:

H1a. Relative Advantage positively contributes to Technological Readiness.

H1b. Simplicity positively contributes to Technological Readiness.

H1c. Compatibility positively contributes to Technological Readiness.

H1d. Data Security positively contributes to Technological Readiness.

Comprising relative advantage, simplicity, compatibility and data security, technological readiness is one of the major components of Big Data Readiness. At a higher level, the relationship between technological readiness and overall Big Data Readiness is presented in the second-order hypothesis as below: 
H1: Technological Readiness positively contributes to Big Data Readiness

\section{Organizational Readiness}

Organizational readiness refers to how employees are prepared and willing to adopt big data analytics depending on the internal and external organizational factors. IT infrastructure and top management support are the two organizational factors often mentioned in technology adoption literature. IT infrastructure is essential for an organization to adopt new applications as it provides the necessary hardware platform, supporting software, computer network, and physical facilities [17, 18]. The more mature an IT infrastructure is, the easier it is for an organization to adopt big data analytics to improve business performance [19].

Top management support for the adoption of a technology is especially important for small and medium enterprises [20]. The chief data officer (CDO) is emerging as an important new executive in the organization due to the arrival of the big data era [21]. This reflects the close relationship between management support and the intention to adopt innovation technology.

While IT infrastructure pertains to the technology resources in an organization, the adequacy of human resources should be maintained with appropriate IT knowledge, skills and experience to enable adoption of big data $[22,23]$.

Financial investment capability refers to the degree to which firms are able to invest in introducing and operating big data [24]. It takes a lot of financial investment to adopt big data in firms, including: equipment, software packages and consulting. The burden of financial costs is likely to cause firms to hesitate before big data adoption [25], leading to the following hypothesis:

H2a. IT Infrastructure positively contributes to Organizational Readiness.

H2b: Top Management Support positively contributes to Organizational Readiness.

H2c: Skills and experience positively contribute to Organizational Readiness.

H2d: Financial investment capability positively contributes to Organizational Readiness.

Like technological readiness, organizational readiness is another pillar contributing to the formation of Big Data readiness at the higher level.

H2: Organizational Readiness positively contributes to Big Data Readiness.

\section{Environmental Readiness}

Adoption of big data analytics may still encounter strong resistance due to inhibiting factors such as switching costs or simply inertia against change [26]. To overcome such reluctance, certain environmental conditions, especially those related to business partners, competitors and government support are needed to push decisionmaking forward [27]. Environmental readiness refers to how organizational users are prepared and willing to adopt big data analytics due to the pressures from outside.

If more and more competitors begin to adopt big data analytics to enjoy its benefits, the decision makers in an organization are likely to feel the pressure to do the same in order to retain competitive advantage. In addition to the pressure from competitors, the pressure from business partners may also be significant. Numerous studies have shown that such a demand from business partners is an important factor affecting the adoption and use of IT applications [28, 29, 16]. Finally, the government policy and support related to open data, cloud computing and industrial promotion may stimulate the adoption of big data $[30,31]$. This leads to the following hypotheses:

H3a. Competitor pressure positively contributes to Environmental Readiness.

H3b. Partner pressure positively contributes to Environmental Readiness.

H3c. Government support positively contributes to Environmental Readiness.

As a major component of Big Data Readiness, environmental readiness is shaped primarily by: competitor pressure, partner pressure and government support.

H3. Environmental Readiness positively contributes to Big Data Readiness.

\section{E. Psychological outcome of Big Data Readiness}

The common psychological outcome variables in the technology adoption literature include attitude toward a technology and intention to use a technology [32]. They are often used in empirical studies as they can be measured with psychometric instruments, just like their antecedents. The following two hypotheses are proposed:

H4a. Big Data Readiness positively affects Attitude toward big data analytics.

H4b. Big Data Readiness positively affects Intention to use big data analytics.

\section{RESEARCH METHODOLOGY}

In order to know the behavioral intention of big data analytics in organizations, we distributed a questionnaire among organizations in different industries in China and received around 180 organizations' feedbacks. Among 178 
valid responses, 130 of them were male (73\%) and 48 (27\%) were female. Each item was measured on a five-point Likert scale from strongly disagree to strongly agree. In order to test the hypotheses, Structural Equation Modeling (SEM) was used to validate the proposed research model. Confirmatory factor analysis (CFA) was performed to examine the overall fit, validity, and reliability of the measurement model. The hypotheses are then examined using the structural model.

\section{RESULTS}

The fit indices of confirmatory factor analysis indicated that the model fit was acceptable considering the large number of variables in the model (Chi-square = 1058.294; model df $=519$; chi-square $/ \mathrm{df}=1.933$; $\mathrm{RMSEA}$ $=0.078 ; \mathrm{CFI}=0.824)$. All factor loadings were well above 0.5 , and composite reliability (CR) coefficients were above 0.7. The overall average variance extracted (AVE) was 0.57 , above the 0.5 threshold. They indicate acceptable convergent validity. To examine the distinctiveness among the formative indicators of each latent variable in the research model, their degrees of collinearity were assessed at different levels. As shown in Table 1, all the variance inflation factors (VIF) were below the threshold of two, suggesting that the formative indicators can be considered independent from each other.

TABLE 1.

COLLINEARITY TEST

\begin{tabular}{|l|c|c|}
\hline Formative indicator & Tolerance & VIF \\
\hline Technological Readiness & .682 & 1.429 \\
\hline - Relative advantage & .633 & 1.588 \\
\hline - Simplicity & .571 & 1.613 \\
\hline - Compatibility & .779 & 1.314 \\
\hline - Data security & .743 & 1.421 \\
\hline & & \\
\hline Organizational Readiness & .648 & 1.485 \\
\hline - IT infrastructure & .839 & 1.193 \\
\hline - Top management Support & .813 & 1.024 \\
\hline - Skills and experience & .724 & 1.187 \\
\hline - Financial investment capability & .667 & 1.279 \\
\hline & & \\
\hline Environmental Readiness & .765 & 1.373 \\
\hline - Competitor pressure & .721 & 1.438 \\
\hline - Partner pressure & .784 & 1.332 \\
\hline - Government support & .811 & 1.384 \\
\hline & & \\
\hline Big Data Readiness & .601 & 1.137 \\
\hline Attitudes towards big data & .688 & 1.322 \\
\hline Intention to use big data & .716 & 1.179 \\
\hline
\end{tabular}

The next step is to test the research hypotheses regarding the relationships between Big Data readiness components and psychological outcomes in terms of intention and attitude. Table 2 shows the results of analysis on the research model. The coefficient of determination (i.e. R-square) of the endogenous latent variable Big Data Readiness was 0.493 , indicating that about $50 \%$ of its variation was explained. All the four components of Technological Readiness were significant, yet Data Security was more salient than the others. Between the four components of Organizational Readiness, Top Management Support was much more important than financial investment capability. On the other hand, government support is much more important than competitive pressure in Environmental Readiness while partner pressure was not a significant factor. Among the three aspects of Big Data Readiness, Technological Readiness was the most salient, and Organizational Readiness is a bit more salient than Environmental Readiness. Finally, Big Data Readiness had significant effects on both psychological outcome variables, Attitude toward and Intention to Use big data.

TABLE 2 .

SEM analysis

\begin{tabular}{|l|c|c|}
\hline Hypotheses & Coefficient & t \\
\hline $\mathrm{H} 1$ & 0.311 & $3.229^{* *}$ \\
\hline - H1a & 0.359 & $3.584^{*}$ \\
\hline - H1b & 0.228 & $2.883^{*}$ \\
\hline - H1c & 0.417 & $3.921^{* *}$ \\
\hline - H1d & 0.482 & $4.562^{* * *}$ \\
\hline & & \\
\hline $\mathrm{H} 2$ & 0.284 & $2.903^{*}$ \\
\hline$-\mathrm{H} 2 \mathrm{a}$ & 0.449 & $6.883^{*}$ \\
\hline$-\mathrm{H} 2 \mathrm{~b}$ & 0.721 & $10.425^{* *}$ \\
\hline$-\mathrm{H} 2 \mathrm{c}$ & 0.599 & $8.132^{* *}$ \\
\hline$-\mathrm{H} 2 \mathrm{~d}$ & 0.226 & $2.620^{*}$ \\
\hline & & \\
\hline $\mathrm{H} 3$ & 0.261 & $2.773^{* *}$ \\
\hline$-\mathrm{H} 3 \mathrm{a}$ & 0.417 & $3.826^{*}$ \\
\hline$-\mathrm{H} 3 \mathrm{~b}$ & 0.159 & 1.156 \\
\hline$-\mathrm{H} 3 \mathrm{c}$ & 0.773 & $11.892^{* *}$ \\
\hline & & \\
\hline $\mathrm{H} 4 \mathrm{a}$ & 0.277 & $3.003^{*}$ \\
\hline $\mathrm{H} 4 \mathrm{~b}$ & 0.348 & $3.619^{*}$ \\
\hline
\end{tabular}

Note. $* * * p<0.001 ; * * p<0.01 ; * p<0.05$.

\section{CONCLUSION}

Based on TOE framework, this study analyzes the adoption intention of big data analytics in China. The hypotheses state that for organizational users to adopt big data analytics, they need to ready their technological, organizational and environmental assets. The empirical results suggest that all three components of Big Data Readiness are indispensable for psychological outcomes. The findings provide researchers and practitioners with some insights into the relative importance of each type of factor to big data adoption.

\section{ACKNOWLEDGMENT}

This research was funded by the Research Committee at the University of Macau.

\section{REFERENCES}


[1] Gil Press, "6 Predictions For The \$203 Billion Big Data Analytics Market," Forbes [online] 2017. Available at https://www.forbes.com/sites/gilpress/2017/01/20/6predictions-for-the-203-billion-big-data-analyticsmarket/\#25a7113e2083

[2] S. Leng, "The big data and AI projects China is pinning its global tech ambitions on," SCMP [online] 2017. Available

at http://www.scmp.com/news/china/economy/article/2 $\underline{126029 / \text { big-data-and-ai-projects-china-pinning-its- }}$ global-tech-ambitions

[3] N. Shah, Z. Irani and A. M. Sharif, "Big data in an HR context: Exploring organizational change readiness, employee attitudes and behaviors," Journal of Business Research, vol. 70, pp. 366-378, 2017.

[4] O. Matthias, I. Fouweather, I. Gregory, A. Vernon, "Making sense of Big Data - can it transform operations management?," International Journal of Operations \& Production Management, vol. 37, no. 1, pp.37-55, 2017.

[5] L. G. Tornatzky, M. Fleischer \& A. K. Chakrabarti. The processes of technological innovation. Lexington, MA.: Lexington Books, 1990.

[6] K. Zhu and K. L. Kraemer, "Post-adoption variations in usage and value of e-business by organizations: cross-country evidence from the retail industry," Information System Research, vol. 16, no. 1, pp. 6184, 2005.

[7] C. Low, Y. Chen, \& M. Wu, "Understanding the determinants of cloud computing adoption," Industrial Management \& Data Systems, vol. 111, no. 7, pp. 1006-1023, 2011.

[8] J. C. Chen, Y. G. Chen, X. Y. Du, C. P. Li, J. H. Lu, S. Y. Zhao and X. Zhou, "Big data challenge: a data management perspective," Front Comput Sci., vol. 7, no. 2, pp. 157-164, 2013.

[9] M. M. Gobble, "Big Data: The next big thing in innovation," Research-Technology Management, vol. 56, no. 1, pp. 64-66, 2013.

[10] N. Park, M. Rhoads, J. Hou and K. M. Lee, "Understanding the acceptance of teleconferencing systems among employees: An extension of the technology acceptance model," Computers in Human Behavior, vol. 39, pp. 118-127, 2014.

[11] E. M. Rogers. Diffusion of innovation (4th ed.). New York, NY: The Free Press, 1995.

[12] A. Lin and N. Chen, "Cloud computing as an innovation: Perception, attitude, and adoption," International Journal of Information Management, vol. 32, no. 6, pp. 533-540, 2012.

[13] G. Moore and I. Benbasat, "Development of an instrument to measure the perceptions of adopting an information technology innovation," Information Systems Research, vol. 2, no. 3, pp. 192-222, 1991.
[14] H. C. Chen, R. H. L. Chiang and V. C. Storey, "Business intelligence and analytics: from big data to big impact," MIS Quarterly, vol. 36, no. 4, pp. 11651188, 2012.

[15] K. Ramamurthy, G. Premkumar and M. R. Crum, "Organizational and interorganizational determinants of EDI diffusion and organizational performance: A causal model," Journal of Organizational Computing and Electronic Commerce, vol. 9, no. 4, pp. 253-285, 1999.

[16] Y. M. Wang, Y. S. Wang and Y. F. Yang, "Understanding the determinants of RFID adoption in the manufacturing industry," Technological Forecasting and Social Change, vol. 77, no. 5, pp. 803-815, 2010.

[17] T. Oliveira and M. F. Martins, "Understanding ebusiness adoption across industries in European countries," Industrial Management \& Data Systems, vol. 110, no. 9, pp. 1337-1354, 2010.

[18] K. Zhu, K. Kraemer and J. Dedrick, "Information technology payoff in ebusiness environments: An international perspective on value creation of ebusiness in the financial services industry," Journal of Management Information Systems, vol. 21, no. 1, pp. 17-54, 2004.

[19] M. Xin and N. Levina, "Software-as-a service model: Elaborating client-side adoption factors," Proceedings of the 29th international conference on information systems. Paris, France, 14-17 December, 2008.

[20] M. Bradford and J. Florin, "Examining the role of innovation diffusion factors on the implementation success of enterprise resource planning systems," International Journal of Accounting Information Systems, vol. 3, pp. 205-225, 2003.

[21] Y. Lee, S. Madnick, R. Wang, F. Wang and H. Y. Zhang, "A cubic framework for the chief data officer: succeeding in a world of big data," MIS Q Executive, vol. 13, no. 1, pp. 1-13, 2014.

[22] T. C. Powell and A. Dent-Micallef, "Information technology as competitive advantage: the role of human, business, and technology resources," Strategic Management Journal, vol. 18, no. 5, pp. 375-405, 1997.

[23] J. W. Lian, D. C. Yen and Y. T. Wang, "An exploratory study to understand the critical factors affecting the decision to adopt cloud computing in Taiwan hospital," International Journal of Information Management, vol. 34, no. 1, pp. 28-36, 2014.

[24] Accenture, Big Success with Big Data, 2014. Available at https://www.accenture.com/t20150523T020852_w /us-en/_acnmedia/Accenture/Conversion- 
Assets/DotCom/Documents/Global/PDF/Digital_1/

Accenture-Big-Data-POV.PDF

[25] Q. Cao, D. R. Jones and H. Sheng, "Contained nomadic information environments: Technology, organization, and environment influences on adoption of hospital RFID patient tracking," Information \& Management, vol. 51, no. 2, pp. 225239, 2014.

[26] G. Polites and E. Karahanna, "Shackled to the status quo: The inhibiting effects of incumbent system habit, switching costs, and inertia on new system acceptance," MIS Quarterly, vol. 36, no. 1, pp. 21-42, 2012.

[27] K. S. Soliman and B. D. Janz, "An exploratory study to identify the critical factors affecting the decision to establish Internet-based interorganizational information systems," Information \& Management, vol. 41, no. 6, 697-706, 2004.

[28] A. Y. L. Chong and K. B. Ooi, "Adoption of interorganizational system standards in supply chains: An empirical analysis of RosettaNet standards," Industrial Management \& Data Systems, vol. 108, no. 4, pp. 529-547, 2008.

[29] C. Low, Y. Chen and M. Wu, "Understanding the determinants of cloud computing adoption," Industrial Management \& Data Systems, vol. 111, no. 7, pp. 1006-1023, 2011.

[30] J. L. Gibbs and K. L. Kraemer, "A cross-country investigation of the determinants of scope of ecommerce use: an institutional approach," Electronic Markets, vol. 14, no. 2, pp. 124-137, 2004.

[31] S. Xu, K. Zhu and J. Gibbs, "Global technology, local adoption: A cross-country investigation of internet adoption by companies in the United States and China," Electronic Markets, vol. 14, no. 1, pp. 13-24, 2004.

[32] V. Venkatesh, M. G. Morris, G. B. Davis, and F. D. Davis, "User acceptance of information technology: Toward a unified view," MIS Quarterly, vol. 27, no. 3, pp. 425-478, 2003. 